\title{
LOS PRINCIPALES HITOS JURISPRUDENCIALES DEL TRIBUNAL EUROPEO DE DERECHOS HUMANOS EN MATERIA DE IGUALDAD DE GÉNERO
}

\author{
ENCARNA CARMONA CUENCA \\ Profesora Titular de Derecho Constitucional \\ Universidad de Alcalá
}

\begin{abstract}
SUMARIO
I. Introducción. II. La igualdad de género en el Convenio Europeo de Derechos Humanos. III. La perspectiva de género como instrumento para la igualdad. IV. Jurisprudencia del TEDH sobre igualdad de género y prohibición de discriminación. V. Jurisprudencia del TEDH sobre derechos humanos con perspectiva de género. VI. Algunas conclusiones.
\end{abstract}

\section{INTRODUCCIÓN}

En este trabajo analizaré algunas de las principales sentencias del Tribunal Europeo de Derechos Humanos (TEDH )sobre la igualdad entre mujeres y hombres o igualdad de género. En los documentos del Consejo de Europa podemos apreciar una evolución desde el reconocimiento de una igualdad meramente formal hasta la consagración de la igualdad material o de facto, como principios esenciales que deben presidir la actuación de los Estados miembros. Además, a partir de los años noventa del pasado siglo, se ha impuesto en el Derecho Internacional de los derechos humanos y en el ámbito europeo el concepto de perspectiva de género o gender mainstreaming, como una técnica o instrumento para conseguir la igualdad entre mujeres y hombres.

Después de una reflexión sobre la igualdad de género en el Convenio Europeo de Derechos Humanos (CEDH), incluidos los Protocolos adicionales, y sobre la aplicación de la perspectiva de género a los derechos humanos, en el trabajo analizo los hitos más importantes en la jurisprudencia del TEDH sobre igualdad de género (formal y material). A pesar de que el sexo es uno de los motivos de discriminación proscritos por el art. $14 \mathrm{CEDH}$, hubo que esperar a 1985 para encontrar una sentencia que estableciera claramente que sólo los motivos más fuertes podían justificar una diferencia de trato por razón de sexo o género. Sin embargo, a partir del año 2000 el Tribunal ha dictado un buen número de sentencias que condenan a los Estados por haber aprobado normas o medidas 
que suponen una discriminación directa contra uno de los géneros (no siempre el femenino). El Tribunal no ha sido tan activo en la apreciación de discriminaciones indirectas, discriminaciones de hecho o en la argumentación en términos de medidas de acción positiva.

A continuación, realizo un análisis de varias sentencias que tratan sobre los derechos de las mujeres desde una perspectiva de género. En algunas de ellas se aplica esta técnica argumentativa, con mayor o menor éxito, y en otras no se tiene en cuenta esta perspectiva en la fundamentación del fallo. Trato de poner de manifiesto ese déficit, pues juzgar con perspectiva de género es fundamental para la superación de la tradicional desigualdad entre hombres y mujeres, para la corrección de la situación de subordinación histórica de las mujeres y para la consecución de la igualdad.

\section{LA IGUALDAD DE GÉNERO EN EL CONVENIO EUROPEO DE DERECHOS HUMANOS}

En contraste con las avanzadas construcciones del Consejo de Europa en materia de igualdad de género ${ }^{1}$, el Convenio Europeo de Derechos Humanos, firmado en el ámbito de aquella organización internacional en 1950, ofrece una protección más clásica y limitada de la igualdad entre mujeres y hombres.

De esta forma, consagra la prohibición de discriminación por razón de sexo — junto con otros motivos de discriminación- en el art. 14 del CEDH, cuyo tenor literal es el siguiente: «El goce de los derechos y libertades reconocidos en el presente Convenio ha de ser asegurado sin distinción alguna, especialmente por razones de sexo, raza, color, lengua, religión, opiniones políticas u otras, origen nacional o social, pertenencia a una minoría nacional, fortuna, nacimiento o cualquier otra situación.»

El Convenio no habla de igualdad de género sino de «distinción por razón de sexo» (entre otros motivos). Lo mismo sucede en la mayor parte de los tratados internacionales de derechos humanos; se sigue hablando del sexo como motivo de discriminación, aunque el término género se ha consolidado en las ciencias sociales como más explicativo de la realidad que $\operatorname{sexo}^{2}$. También se ha consolidado el término género en el ámbito de Naciones Unidas, a partir de la IV Conferencia Mundial sobre la Mujer de Beijing, celebrada en 1995.

El término sexo se refiere a la diferenciación biológica y orgánica entre hombres y mujeres, mientras que la expresión género se refiere a una realidad más amplia, a una construcción simbólica que incluye el conjunto de roles y atributos socioculturales asignados a una persona a partir del sexo al que pertenece, convirtiendo la diferencia sexual en diferencia cultural. Esto es, el concepto género hace alusión a las diferencias sociales entre

1 Vid. S. De Tomás Morales, «La labor del Consejo de Europa en materia de igualdad de género» en R.M. Giles Carnero; M. Mora Ruiz y M.N. Saldaña Díaz (Coords.), Formación y objeto del Derecho antidiscriminatoiro de género: perspectiva sistemática de la igualdad desde el Derecho público, Atelier, Barcelona 2010, pp. 17-32 y E. Carmona Cuenca, «El desarrollo de los instrumentos de protección de los derechos de las mujeres en los sistemas regionales de derechos humanos. A. Sistema Europeo» en E. Carmona Cuenca (Ed.), La perspectiva de género en los Sistemas Europeo e Interamericano de Derechos Humanos, CEPC, Madrid, 2015, pp. 43-84.

2 El TEDH también sigue hablando de «discriminación por razón de sexo» y, por ello, en este trabajo utilizo ambas expresiones. 
hombres y mujeres, que han sido aprendidas y asumidas generación tras generación, que cambian con el paso del tiempo y que presentan muchas variaciones interculturales ${ }^{3}$.

Por otra parte, el CEDH no consagra el principio general de igualdad, sino que establece la prohibición de discriminación únicamente en el disfrute de los derechos reconocidos en el mismo.

Posteriormente, el 1 de noviembre de 1988, entró en vigor el Protocolo Adicional n. 7 (ratificado por España el 16 de noviembre de 2009), cuyo artículo 5 consagra la igualdad jurídica de los esposos en los siguientes términos: «Los cónyuges gozarán de igualdad jurídica de derechos y obligaciones civiles entre sí y en sus relaciones con sus hijos por lo que respecta al matrimonio, durante el matrimonio y en caso de disolución. El presente artículo no impedirá a los Estados tomar las medidas necesarias en interés de los hijos.»

Este artículo no ha tenido una gran virtualidad práctica en la jurisprudencia del TEDH. En las escasas ocasiones en que ha sido alegado, el Tribunal ha considerado que, aunque el precepto consagra la igualdad de derechos de los cónyuges con relación a sus hijos, también es cierto que en su último inciso precisa que el interés de los hijos debe prevalecer sobre aquellos derechos ${ }^{4}$. Y es, precisamente, este último inciso el que impide que tenga una utilidad mayor a la hora de fundamentar por sí mismo una decisión del Tribunal ${ }^{5}$.

Otro hito importante fue la entrada en vigor del Protocolo Adicional n. ${ }^{\circ}$ 12, que contiene una prohibición general de discriminación, ahora no limitada a los derechos enunciados en el Convenio, sino extensiva a cualesquiera derechos fundamentales o legales. Este Protocolo fue abierto a la firma en Roma el 4 de noviembre de 2000 y entró en vigor el 1 de abril de 2005. España lo ratificó el 13 de febrero de 2008.

La gestación de este Protocolo partió de los intentos, a partir de los años sesenta, de incluir en el Convenio garantías suplementarias en el campo de la igualdad y de la no discriminación en general. Pero, como pone de manifiesto el Informe Explicativo del Protocolo n. ${ }^{\circ}$ 12, adoptado por el Comité de Ministros el 26 de junio de $2000^{6}$, fueron los trabajos realizados en los años noventa en el campo de la igualdad entre mujeres y hombres y de la lucha contra el racismo y la intolerancia los que impulsaron este objetivo, que cristalizó en la aprobación del Protocolo n. ${ }^{\circ} 12$.

En el curso de esos trabajos, el Comité Director para la Igualdad entre Mujeres y Hombres (CDEG) subrayó la ausencia, en el marco del Consejo de Europa, de instrumentos específicos de protección jurídica de la igualdad entre mujeres y hombres como derecho fundamental independiente. El CDEG consideraba que una norma jurídica dictada

3 Vid., K. Millet, Política sexual, Cátedra, Madrid, 2017 (1. a edición en inglés de 1970) y J. W. ScOTT, «El género: una categoría útil para el análisis histórico», en AMELANG/NASH (Comp.), Historia y género: las mujeres en la Europa moderna y contemporánea, Alfons, El Magnanim, Valencia,1990

4 Vid., por ejemplo, los casos Hoffmann contra Austria, de 23 de junio de 1993 y Chepelev contra Rusia, de 26 de julio de 2007.

5 E. Carmona Cuenca, «La prohibición de discriminación. Nuevos contenidos (Art. 14 CEDH y Protocolo 12)» en J. García Roca y P. Santolaya (Coords.), La Europa de los Derechos. El Convenio Europeo de Derechos Humanos, CEPC, Madrid, 2014 (3. a ed.), pp. 608-609.

6 http://www.derechoshumanos.net/Convenio-Europeo-de-Derechos-Humanos-CEDH/2000-Protocolo12-ConvenioProteccionDerechosHumanosyLibertadesFundamentales.htm (última fecha de consulta: 29 de mayo de 2018). 
al efecto constituía una de las condiciones esenciales para lograr la igualdad de iure y de facto y concentró sus esfuerzos en la inclusión en el Convenio de un derecho fundamental de la mujer y del hombre a la igualdad.

Sin embargo, el Comité de Derechos Humanos se mostró partidario de un texto basado en el principio de universalidad y expresó sus reservas a un proyecto de Protocolo basado en una aproximación sectorial a la discriminación por motivos de sexo o de raza. Finalmente, la lista de motivos de discriminación del Protocolo n. $^{\circ} 12$ fue idéntica a la del art. $14 \mathrm{CEDH}$. Su art. 1 dispone lo siguiente: «Prohibición general de discriminación: 1 . El ejercicio de cualquier derecho reconocido por la ley será asegurado sin ninguna discriminación fundada, en particular, en razón de sexo, raza, color, lengua, religión, opiniones políticas o de cualquier otro tipo, origen nacional o social, pertenencia a una minoría nacional, riqueza, nacimiento o cualquier otra situación».

Por lo que se refiere a la discriminación por razón de género, el Informe Explicativo del Protocolo n. ${ }^{\circ} 12$ reconoce que en otros Convenios internacionales se han enunciado reglas específicas y más detalladas, exclusivamente dedicadas a esta materia, como en el Convenio sobre la Eliminación de Todas las Formas de Discriminación contra las Mujeres (CEDAW), aprobado por la Asamblea General de Naciones Unidas en 1979. Pero afirma que el Protocolo n. ${ }^{\circ} 12$ no debe ser interpretado como una restricción o una derogación de las disposiciones del Derecho interno o de los tratados que prevean una protección suplementaria contra la discriminación.

Por otra parte, puede considerarse que el Protocolo n. ${ }^{\circ} 12$ del CEDH consagra el principio general de igualdad en toda su amplitud, pues su Preámbulo afirma expresamente en su párrafo tercero que «el principio de no discriminación no impide a los Estados partes adoptar medidas a fin de promover una igualdad plena y efectiva, a condición de que estas medidas respondan a una justificación objetiva y razonable.»

El párrafo transcrito supone una concepción de los principios de igualdad y no discriminación más avanzada que la consagrada en el art. $14 \mathrm{CEDH}$ y que acerca este Protocolo n. ${ }^{\circ} 12$ a otras Declaraciones Internacionales como el mencionado CEDAW o la Carta de los Derechos Fundamentales de la Unión Europea (CDFUE) y también a algunos textos constitucionales estatales como la Constitución española o italiana. En concreto, el art. 23 CDFUE establece el principio de igualdad entre mujeres y hombres y, en su segundo párrafo, dispone que: «El principio de igualdad no impide el mantenimiento o la adopción de medidas que supongan ventajas concretas en favor del sexo menos representado» ${ }^{7}$.

Se puede considerar, así, que el Protocolo n. ${ }^{\circ} 12$ legitima la adopción de las denominadas medidas de acción positiva ${ }^{8}$ para promover la llamada igualdad material. Y ello tiene un evidente interés de cara a la igualdad entre mujeres y hombres, ya que en esta materia los Estados han ido adoptando numerosas medidas de acción positiva con el objetivo de elevar la posición social real de las mujeres en diferentes ámbitos, como el empleo, la educación, la participación social y política, etc.

7 Sobre este precepto, puede verse: E. CARMOna CUENCA, «El principio de igualdad material en la Constitución Europea», en Carrillo, M. y López Bofill, H. (Coords.), La Constitución Europea. Actas del III Congreso de la Asociación de Constitucionalistas de España, Tirant lo Blanch, Valencia, 2006.

8 Sobre las medidas de acción positiva, vid., por ejemplo: M.A. Barrère Unzueta, Discriminación, Derecho antidiscriminatorio y acción positiva en favor de las mujeres, Civitas, Madrid, 1997 y M.A. MARTín VIDA, Fundamento y limites constitucionales de las medidas de acción positiva, Civitas, Madrid, 2002. 


\section{LA PERSPECTIVA DE GÉNERO COMO INSTRUMENTO PARA LA IGUALDAD}

Desde la fecha de aprobación del Convenio Europeo de Derechos Humanos en 1950, el concepto de igualdad de género ha ido enriqueciéndose con nuevos contenidos y el Consejo de Europa ha jugado un importante papel, pionero a escala mundial.

A este respecto, puede distinguirse claramente una evolución desde una posición inicial, que se centró en la eliminación de las discriminaciones legales existentes contra las mujeres y que puede observarse en las primeras recomendaciones y resoluciones (igualdad formal o de iure), hasta una actitud más dinámica, que tiene en cuenta la situación real de las mujeres en las sociedades actuales y que pone de manifiesto la necesidad de adoptar medidas de acción positiva y políticas específicas para conseguir la igualdad material o de facto.

El siguiente paso en la lucha por la igualdad de género viene representado por la adopción de la estrategia del gender mainstreaming, que se ha traducido al español como «transversalización de la perspectiva de género» o «perspectiva de género» ${ }^{9}$. El concepto de gender mainstreaming apareció por primera vez en el ámbito internacional en los años setenta del pasado siglo, a raíz de la declaración de la Década de las Mujeres, realizada por Naciones Unidas en 1975 y tuvo gran difusión en las Conferencias sobre las Mujeres de Naciones Unidas celebradas en Nairobi en 1985 y en Beijing en $1995^{10}$.

La adopción de la estrategia de la perspectiva de género supone un paso más en la consecución de la igualdad de género. No es un fin en sí misma, sino un medio para conseguir la igualdad. Si antes se trataba de establecer políticas públicas sectoriales para conseguir la igualdad material o de hecho de mujeres y hombres (medidas de acción positiva), ahora se trata de una estrategia global, que tiene que implicar a todas y cada una de las políticas públicas para comprobar cuál es su incidencia real en las relaciones entre hombres y mujeres y si tienden realmente a la consecución de la igualdad de hecho y en qué grado.

En numerosas ocasiones se ha puesto de manifiesto que el concepto de perspectiva de género es muy difícil de definir y se presta a gran confusión. La Plataforma de Acción de Beijing ${ }^{11}$ se refirió a él como la necesidad de «tener en cuenta el impacto de género antes de que las decisiones sean adoptadas» ${ }^{12}$. Se trata de que los procesos políticos de toma de decisiones no sean rutinas «ciegas de género ${ }^{13}$ o «sesgadas de género» ${ }^{14}$, es

9 Para una definición del concepto de gender mainstreaming en el Consejo de Europa puede verse el Informe del Grupo de Especialistas sobre incorporación de la perspectiva de género, creado en 1998 en el Consejo de Europa: Gender Mainstreaming. Conceptual Framework, methodology and presentation of good practices. Final Report of Activities of Mainstreaming. Doc EG-S-MS (1998-2 rev. 2004), en: http://www.coe.int/t/dghl/standardsetting/equality/03themes/gender-mainstreaming/EG_S_MS_98_2_rev_en.pdf (última fecha de consulta: 28 de mayo de 2018). Vid., también: H. Charlesworth, «Not Waving but Drowning: Gender Mainstreaming and Human Rights in the United Nations», en Harvard Human Rights Journal vol. 18. Harvard Law School, Cambridge, Massachusetts, 2005 y E. Carmona Cuenca (Ed.), La perspectiva de género..., ob. cit., pp. 27-42.

10 H. Charlesworth, cit., p. 3.

11 Adoptada en la IV Conferencia Mundial sobre la Mujer (Beijing, 1995), de Naciones Unidas.

12 M. Verloo, Gender Mainstreaming: Practice and Prospects, Council of Europe, Strasbourg, 1999, p. 2. En internet: http://www.coe.int/t/dghl/standardsetting/equality/03themes/gender-mainstreaming/EG(1999)13_en.pdf (última fecha de consulta: 29 de mayo de 2018).

13 Traducción del término inglés gender-blind. M. VerLoo, cit., p. 2.

14 Traducción del término inglés gender-biased. M. Verloo, cit., p. 2. 
decir, que tengan en cuenta las diferentes consecuencias que esas decisiones públicas tienen en los hombres y en las mujeres. Estas diferencias son debidas a las relaciones desiguales de poder establecidas entre los géneros desde hace miles de años — desde el Neolítico- y la situación subordinada de las mujeres en la mayor parte de las sociedades, caracterizadas como patriarcales ${ }^{15}$.

La estrategia de la perspectiva de género ha de ser aplicada a todas las facetas de la actividad pública y también a las que tienen que ver con los derechos humanos. A mediados de los años noventa se puso de manifiesto la insuficiencia de los instrumentos sectoriales sobre los derechos de las mujeres, como el CEDAW, y la necesidad de integrar el reconocimiento de las diferencias de género en la interpretación y aplicación de todos los tratados generales sobre derechos humanos ${ }^{16}$. El primer paso hacia la integración de la perspectiva de género en este ámbito se dio en la Conferencia Mundial sobre Derechos Humanos llevada a cabo en Viena en 1993, donde se proclamó que: «la igualdad en la situación de la mujer y sus derechos humanos deben integrarse en las principales actividades de todo el sistema de las Naciones Unidas» ${ }^{17}$.

En el ámbito de los derechos humanos, un análisis con perspectiva de género supone tener en cuenta las diferencias entre mujeres y hombres en el disfrute de los derechos ${ }^{18}$. Se trata de poner de manifiesto que los derechos de las mujeres pueden ser violados de forma diferente a los de los hombres y que determinadas violaciones tienen lugar contra las mujeres por el hecho de serlo. Analizar el efectivo cumplimiento de los derechos humanos con perspectiva de género requeriría un estudio sobre las relaciones reales entre hombres y mujeres y sobre la situación real de las mujeres en las distintas sociedades. También requeriría una reflexión sobre los estereotipos vigentes de lo masculino y lo femenino que posibilitan específicas vulneraciones de los derechos de las mujeres, como el infanticidio femenino, los matrimonios forzados, la violencia de género por parte de actores públicos y privados, la prohibición de realizar determinadas actividades a las mujeres, la imposición de ciertas conductas e indumentarias o las diferentes violaciones de sus derechos sexuales y reproductivos ${ }^{19}$.

En este trabajo analizaré la jurisprudencia del TEDH sobre igualdad y prohibición de discriminación por razón de género (fundamentalmente, a partir del art. 14 CEDH) y también haré referencia a varias sentencias que han comenzado a aplicar la perspectiva de género en diversas materias como la violencia de género, la trata de mujeres con fines de explotación sexual y los derechos sexuales y reproductivos. La limitación de espacio de este trabajo aconseja no extenderse a otras materias que han sido objeto de diversos pronunciamientos del TEDH y que sería también muy interesante tratar, como el velo islámico, el derecho de asilo o los derechos de visita de los hijos de padres separados, entre otras.

15 Sobre el patriarcado, puede verse, por ejemplo: C. Amorós, Hacia una crítica de la razón patriarcal, Antrophos, Barcelona, 1991 y R. M. Coвo Bedla, Fundamentos del patriarcado moderno. Jean Jacques Rousseau, Cátedra/Instituto de la Mujer/Universidad de Valencia, Madrid-Valencia, 1995.

16 E. Tramontana, «Hacia la consolidación de la perspectiva de género en el Sistema Interamericano: avances y desafíos a la luz de la reciente jurisprudencia de la Corte de San José», Revista del Instituto Interamericano de Derechos Humanos n. ${ }^{\circ}$ 53, 2011, p. 144.

17 Idem., p. 145.

18 Sobre los derechos de las mujeres, vid., por ejemplo, M. Macías Jara, «Mujeres», en G. Escobar Roca (Dir.), Derechos sociales y tutela antidiscriminatoria», Thomson Reuters Aranzadi, Cizur Menor, 2012, pp. 1725-1907.

19 H. Charlesworth; C. Chinkin y S. Wright, «Feminist Approaches to International Law», en: American Journal of International Law, vol. 85, Washington DC, 1991, pp. 628 y ss. y E. TramonTANA, cit., p. 145. 


\section{JURISPRUDENCIA DEL TEDH SOBRE IGUALDAD DE GÉNERO Y PROHIBICIÓN DE DISCRIMINACIÓN}

La jurisprudencia del TEDH sobre igualdad entre mujeres y hombres gira en torno a la aplicación del art. $14 \mathrm{CEDH}$. El art. 1 del Protocolo n. ${ }^{\circ} 12$ no ha sido aplicado en esta materia, aunque una Sentencia reciente lo aplica en un caso de discriminación por razón de etnia o raza ${ }^{20}$. El Tribunal parece ser reacio a aplicar este Protocolo, ya que no ha sido ratificado por todos los Estados parte del Convenio.

En la jurisprudencia del Tribunal Europeo, el art. $14 \mathrm{CEDH}$ tiene un carácter dependiente, esto es, sólo puede ser alegado en combinación con algún otro de los derechos reconocidos en el Convenio. Hasta los años noventa del pasado siglo la jurisprudencia sobre este precepto era escasa y también compleja y poco coherente ${ }^{21}$. Y en mayor medida pueden aplicarse estos calificativos a las decisiones del Tribunal Europeo sobre el principio de no discriminación por razón de género.

Sin embargo, esta tendencia está cambiando en los últimos años, sobre todo a partir del cambio de milenio. Podemos encontrar ahora un mayor número de Sentencias que aplican el principio de no discriminación del art. $14 \mathrm{CEDH}$ en general y también referido a la discriminación por razón de género ${ }^{22}$. Para su estudio, agruparé estas sentencias en cuatro apartados: las que argumentan en base a la prohibición de discriminaciones directas; las que se refieren a la prohibición de discriminaciones indirectas, las que aluden a la prohibición de discriminaciones de hecho y las que tratan sobre medidas de acción positiva.

\section{Probibición de discriminaciones directas}

En la mayor parte de las Sentencias que aplican el principio de no discriminación por razón de género del art. $14 \mathrm{CEDH}$, el Tribunal argumenta en base a la prohibición de discriminaciones legales directas, esto es, de aquellas normas que establecen expresamente un trato diferente y desfavorable para uno de los géneros (normalmente las mujeres) sin una justificación objetiva y razonable.

La primera vez que el TEDH se pronunció, expresa y detalladamente, sobre la discriminación basada en el sexo fue en el caso Abdulaziz, Cabales y Balkandali contra Reino Unido, de 28 de mayo de 1985. En esta Sentencia, el Tribunal apreció la vulneración del derecho a la vida privada y familiar del art. $8 \mathrm{CEDH}$ en combinación con la prohibición de discriminación por razón de sexo del art. $14 \mathrm{CEDH}$. La legislación en vigor en el Reino Unido autorizaba a los inmigrantes varones que estaban trabajando legalmente en el país a traer a sus esposas, pero no a las mujeres traer a sus maridos o parejas.

20 Caso Sejdic y Finci contra Bosnia-Herzegovina, de 22 de diciembre de 2009.

21 Carmona Cuenca, E., «La prohibición de discriminación...», cit., p. 588.

22 I. RADACIC, «Gender equality Jurisprudence of the European Court of Human Rights», en: The European Journal of International Law Vol. 19, no. 4, 2008 y A. ViviANI, «La tutela della donna di fronte alla Corte europea dei diritti umani: il discorso di genere arriba a Strasburgo?», en Diritti umani e diritto internazionale, n. ${ }^{\circ} 4$, vol. 1 , 2010 . 
El Tribunal analizó la conformidad con el Convenio de una diferenciación normativa por razón de sexo, entendiendo que, aunque dicha norma tuviese un fin legítimo (en este caso lo era la protección del mercado de trabajo), esta finalidad debería ser suficiente para justificar la diferenciación normativa. Afirmó asimismo que, una vez establecida la importancia de la igualdad de los sexos, serían precisas razones muy fuertes para estimar compatibles con el Convenio tales distinciones, fijando así un estándar que utilizaría en muchos casos posteriores.

A partir de esta Sentencia, podemos encontrar otras que han apreciado vulneración del art. 14 CEDH (en combinación con otro derecho del Convenio) y han constatado la existencia de discriminaciones directas que afectaban a las mujeres, aunque, en un significativo número de casos, los perjudicados por la norma eran los varones. En algunos casos, se trataba de normas que posibilitaban el acceso a ciertos beneficios (como empleo, pensiones, permisos de paternidad o condición de refugiado) o a ciertos derechos (prioridad en el orden de los apellidos). En otros casos, se trataba de la imposición de obligaciones o de la aplicación de condenas penales. Veremos los ejemplos más significativos de cada uno de estos escenarios.

Acceso al empleo. En el caso Emel Boyraz contra Turquía, de 2 de diciembre de 2014, la demandante había aprobado un examen para un puesto de agente de seguridad en una empresa pública. Pero había sido considerada no apta por no cumplir los requisitos de «ser un hombre» $\mathrm{y}$ «haber cumplido el servicio militar». El Tribunal apreció aquí vulneración del art. 14 en combinación con el art. $8 \mathrm{CEDH}$. Afirmó que los motivos que alegaba el Estado demandado sobre la necesidad de usar la fuerza física y de asumir riesgos por trabajar de noche no eran suficientes para justificar esta diferencia de trato, sobre todo, teniendo en cuenta que la demandante ya había trabajado en ese puesto durante cuatro años.

Pensiones. En el caso Wessels-Bergervoet contra Holanda, de 4 de junio de 2002, la demandante consideraba que la diferencia de trato entre hombres casados y mujeres casadas en materia de pensiones constituía una discriminación por razón de sexo (los hombres casados cobraban una pensión de jubilación equivalente al cien por cien del salario, mientras que las mujeres casadas sufrían una reducción, igual que los hombres solteros). El Gobierno holandés justificaba este trato diferente en el hecho de que normalmente eran los maridos los que proveían a las necesidades del hogar. El Tribunal reiteró que sólo las razones más fuertes podían justificar un trato diferente por razón de sexo y de estatus marital y que, en este caso, no existía una justificación objetiva y razonable. Así pues, estimó que se había producido una vulneración del art. 14 combinado con el art. 1 del Protocolo n. ${ }^{\circ} 1 \mathrm{CEDH}$ (derecho de propiedad).

En el caso Willis contra Reino Unido, de 11 de junio de 2002, la argumentación era similar, aunque en este caso el perjudicado era el varón. El demandante era un viudo con dos hijas a quien se había denegado la pensión de viudedad al fallecer su esposa, que era la principal sostenedora económica del hogar, a la edad de treinta y nueve años. Consideraba que la imposibilidad para los varones de beneficiarse de esta prestación, que sí recibían las mujeres, constituía una discriminación por razón de sexo. El Tribunal apreció aquí vulneración del art. 14 en combinación con el art. 1 del Protocolo n. ${ }^{\circ} 1$ CEDH.

Permisos de paternidad. En esta materia es posible observar una interesante evolución en la jurisprudencia del TEDH, desde una posición más tradicional sobre el papel de los padres y las madres en el cuidado de los hijos e hijas hasta una postura más progresiva, que reconoce los avances sociales hacia un reparto equitativo de responsabilidades familiares. 
En el caso Petrovic contra Austria, de 28 de febrero de 1998, el demandante, varón, había solicitado un permiso de paternidad para atender a su hijo después del nacimiento. En la fecha de los hechos, este tipo de permisos estaba previsto en la legislación austríaca para las mujeres trabajadoras, pero no para los hombres en la misma situación, por lo que el demandante consideraba que tales normas eran discriminatorias. El Tribunal no apreció vulneración del art. $14 \mathrm{CEDH}$ y se basó en la falta de uniformidad en las legislaciones de los Estados parte con relación a la concesión de permiso de paternidad a los padres en las mismas condiciones que a las madres.

Sin embargo, en el caso Konstantin Markin contra Rusia, de 7 de octubre de 2010, la solución fue diferente. El Tribunal apreció vulneración del art. 14 en combinación con el art. $8 \mathrm{CEDH}$. El demandante era un militar varón que, después de su divorcio, se había quedado a cargo de los tres hijos del matrimonio. Había solicitado un permiso de paternidad de tres años de duración para atender a sus hijos, que le fue denegado, pues un permiso de tal duración sólo se concedía a las mujeres. El Tribunal Constitucional ruso había avalado la decisión con el argumento de que el permiso de maternidad estaba pensado para permitir a la madre recuperarse del parto y amamantar a sus hijos si lo deseaba. Sin embargo, el Tribunal Europeo consideró que el permiso de paternidad en un momento posterior al nacimiento de los hijos tenía la finalidad de cuidar de éstos y esta labor puede ser realizada tanto por la madre como por el padre. El Tribunal pone de manifiesto que se ha producido una evolución legislativa en los Estados con relación a esta materia y que en la actualidad existe un consenso común europeo en el sentido de hacer posible que tanto el padre como la madre puedan solicitar y obtener un permiso de paternidad o maternidad. A juicio del Tribunal, ello supone que la sociedad europea ha evolucionado hacia una mayor igualdad en el desarrollo de la tarea de educar a los hijos e hijas, habiendo ganado reconocimiento el papel de los padres (varones) en esta labor.

Acceso a la condición de refugiado/a. En el caso Vrountou contra Chipre, de 13 de octubre de 2015, el Tribunal analiza la compatibilidad de la normativa chipriota que extendía todas las prestaciones sociales reconocidas a los refugiados a los desplazados internos por razón del conflicto con Turquía. Pero esta norma contenía una discriminación por razón de género: Los hijos de un padre desplazado tenían los mismos derechos que su progenitor varón, pero los hijos de madre desplazada no tenían acceso a tales beneficios. El Estado demandado justificaba la norma en motivos presupuestarios y en razón del modelo patriarcal de familia prevaleciente en Chipre en el momento en que se adoptó la norma (1974). El TEDH subrayó que las tradiciones o actitudes sociales prevalentes en relación con el papel de la mujer no podían considerarse justificación suficiente de una diferencia de trato por razón de sexo (ni tampoco las razones presupuestarias por sí solas). Apreció vulneración del art. 14 en combinación con el art. 1 del Protocolo 1.

Orden de los apellidos. En el caso Cusan y Fazzo contra Italia, de 7 de enero de 2014, el TEDH analiza la adecuación al Convenio de la legislación italiana que imponía el apellido del padre a los hijos matrimoniales, aún en contra del criterio de sus progenitores. Los demandantes eran unos padres que solicitaron que su hija fuera registrada con el apellido materno. El Tribunal declara la vulneración del art. 14 en combinación con el art. $8 \mathrm{CEDH}$, al considerar que la medida supone una discriminación por razón de sexo e impone al Estado la obligación de modificar la legislación o prácticas internas a fin de cumplir las exigencias derivadas del Convenio. 
Prestación de servicios. En el caso Karlheinz Schmidt c. Alemania, de 18 de julio de 1994, los perjudicados eran los hombres, pues una norma municipal exigía sólo a los varones la prestación de un servicio en el cuerpo de bomberos o, en su defecto, el pago de una cantidad anual, cargas de las que se eximía a las mujeres. El Tribunal apreció vulneración del art. 14 en combinación con el art. 4.3.d) CEDH (obligaciones cívicas).

Condenas penales. En varias sentencias, el TEDH se ha enfrentado a normas que perjudicaban también a los varones, esta vez en materia penal. En el caso L. y V. c. Austria, de 9 de enero de 2003, el Tribunal apreció una discriminación directa desfavorable a los varones. El demandante había sido condenado por mantener relaciones homosexuales con un adolescente mayor de catorce años con el consentimiento de éste. Alegaba que se había producido una discriminación por razón sexo, pues el Código Penal no castigaba las relaciones sexuales de mujeres lesbianas con adolescentes que consentían ni tampoco las relaciones heterosexuales consentidas con menores de la mencionada edad. El Tribunal apreció vulneración del art. 14 en combinación con el art. $8 \mathrm{CEDH}$.

En el caso de Gran Sala Khamtokhu y Aksenchik contra Rusia, de 24 de enero de 2017, el TEDH analiza si la norma penal rusa que regula la cadena perpetua es discriminatoria. Esta medida se aplica a los delitos especialmente graves, pero sólo si los sujetos condenados no son mujeres, menores de 18 años o mayores de 65. En esta ocasión, el Tribunal consideró que tanto las normas internacionales como las europeas establecían que las mujeres debían ser especialmente protegidas frente a los abusos que las mismas sufrían en las cárceles y que también debían ser protegidas las mujeres embarazadas y las madres. En ese contexto de mayor protección, consideró proporcionada la exclusión de las mujeres de la cadena perpetua y, por tanto, estimó que no se había producido discriminación por razón de sexo. Es interesante destacar que esta Sentencia tiene varios Votos Particulares, algunos concordantes y otros disidentes. En concreto, el Juez Pinto de Alburquerque cree que el Tribunal debió plantearse la legitimidad de la cadena perpetua, tanto para mujeres como para hombres.

En la Sentencia Alexandru Enache contra Rumanía, de 3 de octubre de 2017, se dilucidaba una cuestión relacionada con la anterior. En este caso, el demandante alegaba que la norma que permite a las madres suspender la condena de ingreso en prisión por tener un hijo recién nacido, pero no así a los padres, era discriminatoria. Aunque el Tribunal considera que tanto los padres como las madres pueden y deben atender a sus hijos e hijas pequeños/as, como había afirmado en el caso Konstantin Markin contra Rusia ya citado, aprecia diferencias entre las normas laborales y las normas penales. Aplica el principio de proporcionalidad a la diferencia de trato y concluye que ésta estaba objetiva y razonablemente justificada en atención a varias consideraciones: En primer lugar, la legislación estatal permitía al demandante solicitar la suspensión de la condena por otros motivos de salud personal o familiar y, en segundo lugar, el argumento de la especial relación madre-hijo en los primeros meses de vida no puede considerarse irrazonable ni infundado, en especial, teniendo en cuenta que la CEDAW establece que las medidas para proteger la maternidad no deben considerarse discriminatorias. Existen también dos Votos Particulares, uno concordante y otro — de dos jueces_ parcialmente disidente de la mayoría.

Reflexionando sobre estas Sentencias, podemos observar que en algunos casos son las mujeres las que recurren contra normas que las discriminan frente a los varones (en el acceso a ciertos derechos o beneficios) pero en otros casos son los varones quienes recurren 
normas que pretendían proteger a las mujeres, en especial, en relación con la maternidad. El Tribunal ha sido sensible a los cambios sociales acaecidos en Europa en los últimos años, que propugnan un cambio de los roles tradicionales del patriarcado, que situaba a los hombres en el ámbito público y del trabajo remunerado y a las mujeres en el ámbito privado doméstico y del cuidado de los hijos e hijas. Pero, como reconoce el Tribunal en el reciente caso Alexandru Enache, aún está pendiente el desarrollo de una doctrina propia sobre el carácter discriminatorio o no de las normas de protección de la maternidad.

\section{Probibición de discriminaciones indirectas}

El TEDH no ha utilizado en gran medida el concepto de discriminación indirecta por razón de género, a diferencia de otros tribunales como el Tribunal de Justicia de la Unión Europea ${ }^{23}$. Se produce una discriminación indirecta por razón de género cuando una norma o medida utiliza un criterio aparentemente neutro que, sin embargo, en su aplicación, perjudica de modo desproporcionado a uno de los géneros, habitualmente a las mujeres ${ }^{24}$. Recientemente ha comenzado el TEDH a utilizar este concepto en sus argumentaciones, pero sólo ha estimado expresamente producida una discriminación indirecta por razón de género en una Sentencia.

Sí había reconocido claramente el TEDH la existencia de una discriminación indirecta en el caso D.H. y otros contra la República Checa, de 13 de noviembre de 2007 (Gran Sala), pero se trataba de una discriminación por razón de origen étnico.

En la decisión de admisibilidad Hoogendijk contra Países Bajos, de 6 de enero de 2005, el Tribunal incluía una completa definición de la discriminación indirecta por razón de género en los siguientes términos: «Allí donde el demandante pueda establecer, sobre la base de estadísticas oficiales que no admiten polémica, la existencia de un indicio de prueba que indique que una medida — aunque formulada de forma neutral — afecta de hecho a un porcentaje claramente más elevado de mujeres que de hombres, corresponde al gobierno demandado demostrar que dicha medida es el resultado de factores objetivos que no están relacionados con una discriminación por razón de sexo».

En este caso, la demandante alegaba que la aplicación de una norma sobre pensiones de discapacidad perjudicaba en mucha mayor medida a las mujeres que a los varones y aportaba datos estadísticos para apoyar su demanda, considerando que se había producido una discriminación indirecta por razón de género. El Tribunal admitió que habían podido producirse esos efectos discriminatorios respecto de las mujeres casadas o divorciadas que habían sufrido una discapacidad para el trabajo en una fecha determinada (antes del 1 de enero de 1979), pero estimó que esta diferencia de trato tenía una justificación objetiva y razonable. La razón que alegó el Tribunal fue que, en la fecha en que existía la diferencia de

23 Vid., por ejemplo, R. M. GILES CARNERO, «La jurisprudencia del Tribunal de Justicia en materia de igualdad entre hombres y mujeres» en: R. M. GILES CARNERO; M. MORA RUIZ y M.N. SALDAÑA DÍAZ (Coords.), ob. cit., pp. 59-60 y E. CARMONA CUENCA, «La igualdad de género en el Tribunal Europeo de Derechos Humanos: Un reconocimiento tardío con relación al Tribunal de Justicia de la Unión Europea», Revista Española de Derecho Constitucional Núm. 104, 2015, pp. 312-319.

24 Sobre el concepto de discriminación indirecta, vid. O.M. ARNARDótTtro, Equality and Non-Discrimination under the European Convention on Human Rights, Martinus Nijhoff Publishers, The Hague, 2003, pp. 78 y ss. y S. Fredman, (2011), Discrimination Law, Oxford University Press, 2011 (2. ${ }^{a}$ ed.), pp. 177 y ss. 
trato, la realidad mostraba que los varones casados eran mayoritariamente el sostén de la familia y que este hecho justificaba tal diferencia de trato. Consideró la demanda manifiestamente infundada y la inadmitió, perdiendo así una buena oportunidad de aplicar el concepto de discriminación indirecta por razón de género.

En el caso Serife Yigit contra Turquía, de 2 de noviembre de 2010 (Gran Sala), una viuda había planteado una acción de reconocimiento de un matrimonio religioso a fin de obtener determinadas prestaciones sociales. La pretensión fue rechazada en vía administrativa y judicial aduciendo que su matrimonio no estaba reconocido legalmente. La demandante alegaba la existencia de una discriminación indirecta, pues en la medida adoptada sólo resultaban víctimas las mujeres y no los hombres. Ni en la Sentencia de Sección ni en la de Gran Sala, el TEDH se pronunció sobre tal alegación, a pesar de que un Voto Particular había llamado la atención sobre ese déficit en la Sentencia de la Sección, de 20 de enero de 2009. El Tribunal no apreció discriminación y razonó que la diferencia de trato entre matrimonios civiles y religiosos tenía una justificación objetiva y razonable en Turquía, Estado definido como laico donde se intenta proteger y fomentar el matrimonio civil, dado que el matrimonio religioso coloca a las mujeres turcas en una posición de subordinación al varón y produce una acusada limitación de sus derechos fundamentales.

La única ocasión, hasta la fecha, en que el TEDH ha apreciado la existencia de una discriminación indirecta por razón de género fue en el caso Di Trizio contra Suiza, de 2 de febrero de 2016. El Tribunal analizaba la negativa de la Oficina suiza de Seguros de Incapacidad de continuar el pago de una pensión de discapacidad del 50 por ciento a la Sra. Di Trizio después del nacimiento de sus hijos gemelos. Utilizó en su argumentación datos estadísticos y constató que el «método mixto» de cálculo de pensiones de discapacidad a los trabajadores a tiempo parcial, que producía unos resultados perjudiciales para los beneficiarios, se aplicaba en un 98 por ciento de los casos a las mujeres que habían reducido su tasa de actividad después de haber sido madres. Como no se daba una justificación razonable para esta diferencia de trato, el TEDH consideró que se había producido una discriminación indirecta y que había existido violación del art. 14 en combinación con el art. 8 CEDH.

Una vez sentado este precedente, debemos esperar que, cuando el caso lo requiera, en futuras sentencias el Tribunal aprecie la existencia de discriminaciones indirectas por razón de género. El concepto es importante porque da respuesta a discriminaciones que no son fáciles de detectar, pues no aparecen expresamente en las normas, sino que, en buena medida, permanecen ocultas y es preciso realizar estudios estadísticos para hacerlas valer.

\section{Probibición de discriminaciones de becho}

El caso Zarb Adami c. Malta, de 20 de junio de 2006, se refería a una discriminación por razón de género. La demandante alegaba que se había producido una discriminación en la aplicación de la ley sobre jurados. Aunque en la ley sobre jurados no se establecía ninguna disposición en este sentido, durante los cinco años anteriores a los hechos sólo el 3,05 por ciento de los jurados habían sido mujeres frente al 96,95 por ciento de hombres. A la demandante, que había participado en varias ocasiones, se le había multado por no participar en uno de esos jurados.

Aunque en este caso parece que el TEDH argumenta en términos de discriminación indirecta (sin decirlo expresamente) pues habla de una «medida neutral» que, en su 
aplicación, tiene efectos perjudiciales para un grupo, en realidad se trata de una discriminación de hecho, pues en la norma sobre composición de jurados no se contenía ninguna previsión que afectara en mayor medida a las mujeres. Fue la aplicación práctica de la norma la que produjo la discriminación y así lo reconoció el propio Tribunal en un caso posterior ${ }^{25}$.

\section{Medidas de acción positiva}

Según una comprensión avanzada del principio de igualdad, la prohibición de discriminación no impide la adopción de medidas que, aunque sean aparentemente desiguales, en realidad tienden a la consecución de la igualdad material. Así pues, las medidas de acción positiva serían aquellas normas que favorecen a colectivos que se encuentran en situación de desventaja en una sociedad y precisamente para compensar esa desventaja. Una finalidad típica de aplicación de estas medidas, ya desde su origen en el Derecho antidiscriminatorio estadounidense de los años sesenta, fue facilitar la incorporación al trabajo remunerado de colectivos que tenían dificultades para acceder a él, como los afrodescendientes y las mujeres ${ }^{26}$.

El art. 14 CEDH no afirma expresamente esta dimensión del principio de igualdad, como sí hace el Preámbulo del Protocolo n. ${ }^{0} 12$, según hemos visto ${ }^{27}$. Pero ya antes de la aprobación de este Protocolo, el Tribunal Europeo había aplicado la doctrina conocida como «discriminación por indiferenciación» en el caso Thlimmenos contra Grecia, de 6 de abril de 2000. En este caso se amplía el campo de la prohibición de discriminación enunciada en el art. $14 \mathrm{CEDH}$, al establecer que dicho precepto «es también transgredido cuando, sin justificación objetiva y razonable, los Estados no aplican un trato distinto a personas cuyas situaciones son sensiblemente diferentes».

El Tribunal de Estrasburgo ha hecho un escaso uso del concepto de acción positiva, a diferencia, una vez más, del Tribunal de Justicia de la Unión Europea ${ }^{28}$, de quien parece haber tomado esta construcción. Aunque sin emplear la expresión «medidas de acción positiva», en el caso Stec y otros contra Reino Unido, de 12 de abril de 2006, se argumenta en base al art. $14 \mathrm{CEDH}$, complementado con la doctrina Thlimmenos, para justificar la adopción de medidas que favorecían a las mujeres trabajadoras con relación a los varones. Dichas medidas consistían en la fijación, desde 1940, de una edad de jubilación inferior para las mujeres que para los hombres. En opinión del Tribunal, estas medidas estaban encaminadas, en su origen, a corregir la desventaja que sufrían las mujeres en el plano económico. Aunque en la fecha de la Sentencia la situación de mujeres y hombres era distinta y más igualitaria, consideró que la diferencia seguía siendo razonable y otorgó un amplio margen de apreciación al Estado para fijar un calendario de reformas.

Posteriormente en el caso Andrle contra República Checa, de 17 de febrero de 2011, se reiteran estos razonamientos en un supuesto similar. En este caso sí se menciona

25 En el caso D.H. contra la República Checa, de 13 de noviembre de 2007, ya citado.

26 Vid. E. Carmona Cuenca, «Igualdad de género y Derecho antidiscriminatorio. La Constitución española de 1978, en E. Carmona Cuenca e I. Garrido Gómez (Coords.), Diversidad de Género e Igualdad de Derechos. Manual para una asignatura interdisciplinar, Tirant lo Blanch, Valencia, 2017 (2. ${ }^{a}$ ed.), pp. 79-81.

27 Vid., supra, epígrafe II.

28 Vid. R.M. Giles Carnero, cit., pp. 61-72 y E. Carmona Cuenca, «La igualdad de género en el Tribunal Europeo...», cit., pp. 319-323. 
expresamente el concepto de «acción afirmativa». También aquí la legislación checa fijaba una edad mínima inferior a las mujeres para poder recibir una pensión. El demandante alegaba que él había tenido la custodia de los hijos y se había dedicado a su cuidado. Pero el Tribunal estimó que la diferencia entre varones y mujeres había tenido una justificación histórica en la Checoslovaquia socialista y que el Estado checo gozaba de un amplio margen de apreciación para ir adaptando la normativa a la realidad actual. No apreció tampoco vulneración del art. $14 \mathrm{CEDH}$.

De esta escasa jurisprudencia del TEDH sobre las medidas de acción positiva podemos concluir que las normas cuestionadas y finalmente legitimadas por el Tribunal no pueden considerarse propiamente medidas de acción positiva, pues no fomentan la incorporación de la mujer al trabajo remunerado, sino que más bien parecen perpetuar el modelo tradicional de reparto de trabajo entre hombres y mujeres ${ }^{29}$.

\section{JURISPRUDENCIA DEL TEDH SOBRE DERECHOS HUMANOS CON PERSPECTIVA DE GÉNERO}

La incorporación de la perspectiva de género a la jurisprudencia del TEDH se ha producido recientemente y, en general, sin aludir a este término. Esto último no deja de resultar curioso, teniendo en cuenta que la técnica de la perspectiva de género se ha consolidado ya hace tiempo en los distintos documentos internacionales sobre derechos humanos, en especial, en los documentos del Consejo de Europa, como hemos visto ${ }^{30}$.

En muchos casos, el Tribunal ha tenido que decidir sobre vulneraciones de derechos humanos sufridas por mujeres. Pero sólo en algunos de estos asuntos ha analizado dichas vulneraciones teniendo en cuenta los estereotipos sociales vigentes en todas las sociedades actuales, que atribuyen un papel dominante a los varones y un rol subordinado a las mujeres, es decir, han aplicado una perspectiva de género. En una valoración general, este análisis ha sido insuficiente, los problemas reales desbordan con mucho la aproximación realizada por el Tribunal de Estrasburgo. Pero no dejan de ser los primeros pasos de un camino que habrá que recorrer en el futuro inmediato.

Las materias que vamos a estudiar aquí y en las que el Tribunal ha aplicado la perspectiva de género o debería haberlo hecho son: La violencia contra las mujeres, incluida la trata con fines de explotación sexual y los derechos sexuales y reproductivos.

\section{La violencia contra las mujeres}

La «violencia contra las mujeres» o «violencia de género» se caracteriza porque las víctimas son mujeres y los agresores son varones y, además, porque la violencia se ejerce

29 En este sentido, I. RADACIC, cit., p. 851. El Tribunal Constitucional español sí ha realizado esta distinción entre normas aparentemente protectoras de las mujeres en el ámbito laboral y medidas de acción positiva, que favorecen la incorporación de las mujeres al trabajo. Vid. F. REY MARTíNEZ, «La igualdad entre mujeres y hombres en la jurisprudencia del Tribunal Constitucional español» en R.M. Giles Carnero, M. Mora Ruiz y M.N. Saldaña DíaZ, ob. cit., pp. 95-109 y E. CARmona CuenCA, «Igualdad de género y Derecho antidiscriminatorio», cit. pp. 77-78.

30 Vid., supra, apartado III. 
contra la mujer por el hecho de ser mujer y está relacionada con los estereotipos establecidos históricamente para cada uno de los géneros ${ }^{31}$. Como se ha visto, en las sociedades patriarcales estos estereotipos asignan un papel dominante a los varones y un papel subordinado a las mujeres. La violencia sería una forma extrema de asegurar esta relación de dominación-subordinación, por eso la tendencia actual en los organismos internacionales es considerar esta forma de violencia como una manifestación extrema de discriminación por razón de género ${ }^{32}$.

Existen, básicamente, dos modalidades de violencia contra las mujeres, una es aquella que se produce en el ámbito familiar o afectivo cuando entre el agresor y la víctima existe o ha existido algún vínculo sentimental y otra es aquella producida por agentes externos a la pareja o familia, bien sean agentes estatales o bien agentes privados, con la posible aquiescencia del Estado.

En la jurisprudencia del TEDH son destacables los asuntos que se han producido en el ámbito del matrimonio o de la pareja sentimental, aunque también han llegado casos de violencia contra las mujeres producida por otros agentes externos públicos o privados. En algunos de los asuntos analizados se ha hecho — con mayor o menor fortuna- un análisis cercano a la perspectiva de género.

Hace tiempo que el Tribunal de Estrasburgo conoce asuntos relativos a la violencia de género ejercida por los hombres contra las mujeres que son o han sido sus parejas. Hasta 2009 trató estos casos como violencia individualizada y no como un problema social global, es decir, no aplicaba la perspectiva de género.

En el caso Kontrová contra Eslovaquia, de 31 de mayo 2007, el origen de la demanda era una situación de violencia machista en el ámbito familiar. Las pretensiones de la demandante estaban relacionadas con los malos tratos sufridos por ella, con la muerte de sus dos hijos a manos de su marido y con la falta de un recurso efectivo que le permitiera ver compensado el daño moral que le causaron estas muertes. El Tribunal utilizó la doctrina de las obligaciones positivas del Estado en la protección del derecho a la vida (art. 2 CEDH) para afirmar que, en determinadas circunstancias, estas obligaciones incluyen el deber de las autoridades estatales de adoptar las medidas preventivas adecuadas y efectivas para proteger la vida de las personas que se encontraban en una situación conocida de riesgo.

Esta doctrina fue reiterada en el caso Branko Tomasic y otros contra Croacia, de 15 de enero de 2009, en el que los demandantes eran los padres y los hermanos de una mujer asesinada por su marido, quien también mató a la hija de ambos, de un año de edad. Pero se hizo un tratamiento individualizado o «neutral» de los asesinatos, sin hacer una reflexión general sobre lo que supone la violencia de género como problema social; en suma, no se analizó el caso con perspectiva de género ${ }^{33}$.

El caso Bevacqua contra Bulgaria, de 12 de junio de 2008, supuso un punto de inflexión en esta materia. Por una parte, porque el TEDH tomó en consideración algunos

31 Vid. E. Carmona Cuenca, «El desarrollo de los instrumentos de protección de los derechos de las mujeres..., cit., pp. 68 a 74 e I. TurÉGano MANSILla, «Derecho y violencia contra las mujeres: la perspectiva feminista» en M.A. Zurilla Cariñana y P. Domínguez Martínez (Coords.), Violencia contra las mujeres. Un enfoque jurídico, Septem Ediciones, Oviedo, 2011.

32 Por ejemplo, en la Declaración y Plataforma de Acción de Beijing de 1995 (Párrafo 118). En Internet: http://www.un.org/womenwatch/daw/beijing/pdf/BDPfA\%20S.pdf (última consulta: 6 de junio de 2018).

33 A. Queralt Jiménez, «La violencia contra las mujeres. A. Sistema Europeo», en E. Carmona Cuenca, La perspectiva de género..., ob. cit., pp. 221-222. 
instrumentos internacionales contra la violencia de género. Y, sobre todo, porque abrió una nueva línea argumental que podría ser aplicada, entre otros casos, a las mujeres que sufren violencia por parte de sus parejas o exparejas, al identificarlas como grupos vulnerables a los que es preciso proteger y con respecto a los cuales hay que entender reforzadas las obligaciones positivas del Estado.

Sin embargo, esta Sentencia resultó decepcionante por una razón. La demandante, víctima de malos tratos por parte de su marido, había solicitado que el delito de violencia de género se considerase público, es decir, perseguible de oficio y sin necesidad de participación de la víctima. El Tribunal consideró que el Estado había incumplido sus obligaciones positivas de protección, pero afirmó que el Convenio no impone una forma específica de cumplir esas obligaciones (persecución penal o carácter público del delito) sino que la elección de las concretas medidas a adoptar corresponde a cada Estado. Esta afirmación del TEDH constituyó un déficit importante en la lucha contra la violencia machista, pues la fijación de un marco jurídico específico en esta materia redundaría en una protección más adecuada y eficaz de las víctimas ${ }^{34}$. Se perdió aquí otra buena oportunidad para analizar el asunto con perspectiva de género, es decir, teniendo en cuenta la especial vulnerabilidad de las víctimas de este tipo de violencia, que sufren una situación de miedo, indefensión y debilidad.

El hito más importante, hasta la fecha, entre los pronunciamientos del TEDH sobre violencia de género, es el caso Opuz contra Turquía, de 9 de junio de 2009. En este caso, la demandante era una mujer que había sido víctima de malos tratos por parte de su marido, quien también había asesinado a la madre de su esposa. Fue la primera vez que se declaró vulnerado el art. $14 \mathrm{CEDH}$ en combinación con los arts. 2 y $3 \mathrm{CEDH}$, al reconocer que la violencia sufrida por la demandante estaba basada en motivos de género, lo cual equivale a una forma de discriminación contra las mujeres. Se tuvo en cuenta aquí el elevado número de casos de violencia contra las mujeres a manos de sus maridos o ex maridos en Turquía, la pasividad del sistema judicial y la impunidad de la que gozaban los agresores.

En esta Sentencia se contiene la argumentación más completa dictada hasta la fecha por el TEDH en la materia. Se citan numerosos instrumentos internacionales sobre prohibición de discriminación por razón de género y de lucha contra la violencia hacia las mujeres, se recuerdan las obligaciones positivas del Estado para la protección de la vida y la integridad física y psíquica y, lo que es más destacable, se establecen una serie de elementos que las autoridades estatales deben tener en cuenta a la hora de proseguir un procedimiento por violencia de género, aún en el caso de que la víctima retire la denuncia. Se puede afirmar que en esta Sentencia sí se analizó el caso con perspectiva de género ${ }^{35}$.

Ahora bien, esta jurisprudencia no ha sido reiterada en todos los casos posteriores. Algunos de ellos han seguido siendo tratados como casos individuales de violencia, aunque hayan supuesto ciertos avances en la lucha contra la violencia de género. El caso E.S. y otros contra Eslovaquia, de 15 de septiembre de 2009, fue importante por dos motivos. En primer lugar, porque el TEDH hace especial énfasis en la necesidad de que las medidas internas de protección de las víctimas de la violencia sean eficaces y, en segundo 
lugar, porque, a pesar de ser posterior al Caso Opuz, no se hace ninguna referencia a la violencia de género como realidad o situación discriminatoria contra la que es preciso luchar, sino que, más bien, se realiza un estudio «neutral» de los hechos, ajeno a la perspectiva de género.

En el caso Hajduová contra Eslovaquia, de 30 de noviembre de 2010, se argumentaba en torno a la especial vulnerabilidad de las mujeres víctimas de la violencia por parte de sus parejas masculinas y a las especiales obligaciones del Estado para su protección y se apreció vulneración del art. $8 \mathrm{CEDH}$, pero no se consideró lesionado el art. $14 \mathrm{CEDH}$. Y en el caso A. contra Croacia, de 14 de octubre de 2010, se ha seguido afirmando que el Estado puede elegir las medidas que considere más apropiadas para luchar contra esta forma de violencia.

En otros casos recientes, sin embargo, sí se ha aplicado la doctrina Opuz, considerando que se ha vulnerado el art. 14 en relación con el art. 3 (prohibición de tortura y malos tratos) CEDH. Se trata de tres Sentencias de 2013 y 2014, todas contra Molda$\mathrm{via}^{36}$, en las que se pone de manifiesto la grave situación de discriminación que padecen las mujeres en ese país.

Así pues, la avanzada línea abierta en el Caso Opuz no se ha seguido de forma homogénea en la jurisprudencia posterior sobre violencia de género. Es deseable que el Tribunal Europeo trace un marco general en este sentido para luchar contra esta grave y persistente vulneración de los derechos fundamentales de las mujeres y para ello es preciso juzgar estos casos con perspectiva de género. La asunción de la idea de que la violencia de género es un mecanismo extremo para perpetuar la desigualdad entre hombres y mujeres es un avance para erradicar estas conductas y el reconocimiento de que en estos casos se han vulnerado varios derechos del Convenio (arts. 2, 3 y 8 fundamentalmente) en combinación con la prohibición de discriminación del art. $14 \mathrm{CEDH}$ es un paso importante en la buena dirección.

Recientemente, podemos destacar dos sentencias que se refieren a la violencia contra las mujeres por parte de agentes externos, fuera de la pareja o expareja. La primera de ellas, el caso Y contra Eslovenia, de 28 de mayo de 2015, es considerada por el Tribunal como un case report. El asunto parte de la denuncia penal de una mujer contra un amigo de su familia a quien acusa de haberla agredido sexualmente cuando ella era menor de edad, alegando que el proceso judicial había sido excesivamente largo y traumático para ella. El Tribunal alerta en su Sentencia sobre la actuación de las autoridades policiales y judiciales en casos de violencia contra las mujeres, recordando que en muchas ocasiones no se tiene en cuenta la necesidad de especial protección de la mujer que ha sido víctima de estos hechos. Apreció vulneración de la vertiente procesal del art. $3 \mathrm{CEDH}$ por la excesiva duración del proceso y porque las autoridades nacionales permitieron numerosos interrogatorios a la víctima, diversas exploraciones y un interrogatorio intimidatorio y humillante, con comentarios ofensivos.

Una situación similar se dio en el caso G.U. contra Turquía, de 18 de octubre de 2016. Hubo una sentencia absolutoria interna contra el padrastro de la víctima de una agresión sexual, si bien el motivo de tal absolución era la impotencia del agresor, lo que no debió descartar los abusos sexuales, a juicio del TEDH. El Tribunal consideró que en

36 Casos Eremia, Mudric y TM y CM, todos ellos contra Moldavia, de fechas 18 de mayo de 2013, 16 de julio de 2013 y 28 de enero de 2014 , respectivamente. 
el proceso penal interno debió tenerse en cuenta la peculiar situación de vulnerabilidad de la víctima, también una menor, algo que no se dio por distintos motivos: La víctima no recibió apoyo psicológico prestado por una mujer, se denegó su solicitud de que su declaración fuera realizada en sesión no pública, sus declaraciones ante la policía se realizaron ante agentes masculinos, etc. Por todo ello se consideraron vulnerados los arts. 3 y $8 \mathrm{CEDH}$.

Estas dos sentencias sí analizan las agresiones sexuales a niñas con perspectiva de género, pues ponen de manifiesto la especial vulnerabilidad de las víctimas y muestran las insuficiencias de las actuaciones policiales y judiciales.

\section{La trata de mujeres con fines de explotación sexual.}

Como ponen de manifiesto los documentos del Consejo de Europa, la trata de seres humanos es una forma específica de violencia y una forma moderna de esclavitud que supone una grave violación de los derechos humanos ${ }^{37}$. Es un fenómeno que ha de analizarse con perspectiva de género, pues la mayor parte de las víctimas de trata son mujeres y niñas y, en un alto porcentaje, son tratadas con fines de explotación sexual ${ }^{38}$. Esta forma de trata constituye una manifestación más de las relaciones desiguales entre los géneros y de la consideración de las mujeres como objetos sexuales a disposición de los varones. Por tanto, puede considerarse una forma de violencia contra las mujeres.

La primera vez que el Tribunal se pronunció expresamente sobre la trata de mujeres con fines de explotación sexual como una vulneración de derechos humanos fue en el importante caso Rantsev contra Chipre y Rusia, de 7 de enero de 2010. El demandante, el Sr. Rantsev, de nacionalidad rusa, alegaba vulneración de los arts. 2, 3, 4, 5 y 8 CEDH causados por la trata de su hija, de veinte años de edad, para su explotación sexual y su posterior muerte violenta en Chipre.

Lo más interesante de este caso es que el TEDH incluye la trata de mujeres con fines de explotación sexual en el ámbito normativo del art. $4 \mathrm{CEDH}$ (prohibición de esclavitud y trabajos forzados) y, en consecuencia, le aplica su doctrina de las obligaciones positivas del Estado en relación con este precepto. La Sentencia condenó a los Estados demandados por vulneración de este precepto (a Chipre por infracción material y a Rusia por infracción formal). Sin embargo, no apreció vulneración de los arts. 2 y $3 \mathrm{CEDH}$, pues no consideró demostrado que la víctima sufriera malos tratos antes de su muerte ni que la muerte fuera consecuencia de violencia ejercida contra ella.

37 En especial, el Convenio del Consejo de Europa sobre la Acción contra la Trata de Seres Humanos, en vigor desde el 1 de febrero de 2008. En el ámbito de Naciones Unidas hay que destacar el Protocolo para Prevenir, Reprimir y Sancionar la Trata de Personas, especialmente Mujeres y Niñas (Protocolo de Palermo), de 2000. Vid. E. Carmona Cuenca, «El desarrollo de los instrumentos de protección de los derechos de las mujeres..., cit., pp. 75-77.

38 Vid. E. Carmona Cuenca, «Mujeres prostituidas y mujeres víctimas de la trata: la incorporación de la perspectiva de género a la jurisprudencia del Tribunal Europeo de Derechos Humanos», en R. Serra Cristóbal (Coord.), La discriminación múltiple en los ordenamientos jurídicos español y europeo, Tirant lo Blanch, Valencia, 2013, pp. 223-244. 
El Tribunal podría haber realizado un análisis más claro en clave de género, poniendo de manifiesto cómo la realidad de la trata con fines de explotación sexual afecta de forma muy diferente a mujeres y a hombres ${ }^{39}$, apareciendo en su inmensa mayoría aquéllas como víctimas y éstos como tratantes. También podría haber reflexionado sobre la situación de vulnerabilidad de las víctimas de trata y sobre la consideración de la explotación sexual como trato inhumano y degradante.

Por lo que se refiere a los efectos de la Sentencia, en este caso el Tribunal podría haber ido más allá de su condena al Estado. Siguiendo el ejemplo de la Corte Interamericana de Derechos Humanos en cuanto a las reparaciones establecidas en casos de violencia contra las mujeres ${ }^{40}$, podría haber impuesto algún tipo de reparación tendente a proteger a las víctimas y a prevenir la trata de mujeres en el futuro.

En el caso L.E. contra Grecia, de 21 de enero de 2016, el TEDH vuelve a enfrentarse con la trata de mujeres con fines de explotación sexual y parece ir un poco más allá en la fijación de obligaciones estatales para la prevención de esta lacra. La demandante era una mujer nigeriana que había sido obligada a prostituirse en diversas ciudades griegas durante dos años mediante el uso del vudú. Las autoridades griegas tardaron en reconocerle el estatus de víctima de trata, retraso que provocó la huida del tratante. El Tribunal aplica la jurisprudencia sentada en el caso Rantsev y recuerda las obligaciones positivas que corresponden a los Estados en materia de trata, subrayando que deben tener un marco jurídico apropiado que permita sancionar a los culpables del delito, prevenir éste y proteger a las víctimas. Asimismo, recuerda las obligaciones de los Estados de desarrollar una investigación efectiva cuando tengan conocimiento de que se ha producido un caso de trata. En este caso también consideró vulnerado el art. $4 \mathrm{CEDH}$, pero tampoco realizó el Tribunal un análisis de la trata con fines de explotación sexual con perspectiva de género. Ello hubiera requerido un estudio de la especial vulnerabilidad de estas víctimas y de la especial protección que debió prestar el Estado. También hubiera requerido una reflexión sobre la consideración de la explotación sexual como trato inhumano y degradante.

En una Sentencia reciente, el caso V.C. contra Italia, de 1 de febrero d 2018, el TEDH condenó al Estado por incumplimiento de las obligaciones positivas relacionadas con el art. $3 \mathrm{CEDH}$ (prohibición de tortura y tratos inhumanos y degradantes). El motivo fue la falta de protección adecuada de una adolescente con una enfermedad psíquica y toxicómana, que fue víctima de una red de explotación sexual. El Estado se retrasó mucho en ofrecer la protección que habían solicitado los padres (internamiento en un centro especializado), aun teniendo conocimiento del riesgo que corría la menor. El avance que supone este caso consiste en la consideración de que se ha vulnerado la prohibición de tratos inhumanos y degradantes del art. $3 \mathrm{CEDH}$ y el derecho a la vida privada del art. 8 CEDH. El Tribunal ha tenido en cuenta que la víctima era menor y, además, tenía una enfermedad psíquica. Pero una reflexión con perspectiva de género tomaría en consideración que también las mujeres mayores de dieciochos años sometidas a explotación sexual son muy vulnerables y, asimismo, víctimas de tratos inhumanos y degradantes, cuando no de tortura.

39 En la Sentencia, el TEDH menciona en alguna ocasión que la mayor parte de las víctimas son mujeres y niños/as, pero sin analizar a fondo esta cuestión ni obtener conclusiones específicas sobre ella.

40 Por ejemplo, en el caso González y otras contra México (caso Campo Algodonero), de 16 de noviembre de 2009. 


\section{Los derechos sexuales y reproductivos}

Cualquier análisis sobre el cumplimiento efectivo de los derechos sexuales y reproductivos ha de realizarse necesariamente con una perspectiva de género, dado el especial papel de la mujer en la reproducción.

Las cuestiones sobre las que se ha pronunciado el TEDH han sido las siguientes:

1. El acceso de las mujeres a los servicios de salud durante el embarazo, parto y postparto o derecho a una maternidad segura;

2. La utilización de métodos anticonceptivos y la prohibición de esterilizaciones forzadas;

3. la regulación del aborto,

4. el acceso a las técnicas de reproducción asistida y

5. la denominada «gestación subrogada».

En general, la jurisprudencia del Tribunal de Estrasburgo en esta materia presenta varias contradicciones y puntos oscuros. Es frecuente la remisión al margen de apreciación estatal en lugar de adoptar decisiones claras sobre materias complejas como el aborto o las técnicas de reproducción asistida. También es posible percibir que en esta jurisprudencia no existe un esfuerzo claro por aplicar una perspectiva de género que tenga realmente en cuenta la especial incidencia que las materias relativas a la reproducción tienen sobre las mujeres ${ }^{41}$. Aquí sólo podré hacer referencia a algunas de las sentencias más significativas en esta materia ${ }^{42}$.

El acceso de las mujeres a los servicios de salud durante el embarazo, parto y postparto o derecho a una maternidad segura. En el caso Ternovszky contra Hungría, de 14 de diciembre de 2010, el TEDH parecía haber construido, a partir del art. 8 CEDH, un derecho de las mujeres embarazadas a decidir sobre las circunstancias del parto y, en concreto, a dar a luz en su domicilio, aunque no llegó a afirmar que existiese una obligación de los Estados de garantizar, en todo caso, la asistencia médica a las mujeres que decidiesen dar a luz en su domicilio.

Sin embargo, en el caso Dubská y Krejzová contra República Checa, de 15 de noviembre de 2016 (Gran Sala), el TEDH afirmó que la prohibición a las matronas de atender partos en el domicilio - lo que suponía, en la práctica, la prohibición de estos partos- no constituía vulneración del Convenio. En esta Sentencia, que cuenta con un Voto Particular discrepante firmado por cinco Jueces, sólo se hace una referencia tangencial a los derechos sexuales y reproductivos de las mujeres. Se recomienda a las autoridades nacionales que sigan avanzando en la revisión de la normativa vigente sobre los nacimientos en el domicilio de acuerdo a criterios médicos y científicos, de manera que se respeten los derechos reproductivos de las mujeres.

La utilización de métodos anticonceptivos y la prohibición de esterilizaciones forzadas. El TEDH ha reconocido un derecho de toda persona a que se respete su decisión de

41 M. Díaz Crego, «Los derechos sexuales y reproductivos. A. Sistema Europeo», en E. Carmona Cuenca, La perspectiva de género..., ob. cit., pp. 182-183.

42 Para un desarrollo más extenso, vid. M. DíAz CREGo, cit. 
ser o no madre/padre vinculado al derecho a la vida privada y familiar del art. $8 \mathrm{CEDH}^{43}$. Con relación al uso de anticonceptivos, el TEDH se pronunció en el caso Pichon y Sajous contra Francia, Decisión de 2 de octubre de 2001, afirmando que no existía un derecho de los farmacéuticos a negarse a vender píldoras anticonceptivas, dificultando, así, el acceso a estos medicamentos por parte de la población.

Con relación a la esterilización forzada, el Tribunal consideró, en el caso V.C. contra Eslovaquia, de 8 de noviembre de 2011, que la esterilización de una ciudadana de etnia romaní sin que se le hubiese informado previamente de la naturaleza y el alcance de la intervención constituía vulneración de los arts. 8 y 3 CEDH. En una sentencia más reciente, el caso Soares de Melo contra Portugal, de 16 de febrero de 2016, el Tribunal consideró contrario al art. $8 \mathrm{CEDH}$ la exigencia a una mujer de que se sometiera a una operación de esterilización como condición para conservar la custodia de sus diez hijos e hijas. En esta sentencia se argumenta en base a los derechos reproductivos de las mujeres y se critica que las autoridades no ofreciesen a la recurrente otras posibilidades de control de natalidad y que se prohibiese todo contacto entre madre e hijos, sin tener en cuenta que no habían existido malos tratos a los menores y que éstos tenían una especial vinculación emocional con su madre.

La regulación del aborto. La posición del TEDH en materia de aborto ha sido ambivalente, tratando de llegar a un difícil equilibrio entre los derechos de la mujer embarazada y las creencias, fuertemente arraigadas en algunos Estados europeos, sobre la defensa de la vida del feto. El TEDH no ha reconocido nunca el derecho del feto a la vida, pero tampoco ha reconocido un derecho de la mujer a abortar ${ }^{44}$. Y lo que no ha hecho nunca el TEDH es declarar que una legislación nacional sobre el aborto es contraria al Convenio. Más bien al contrario, de la jurisprudencia del Tribunal de Estrasburgo parece deducirse un notable margen de apreciación estatal, lo que no se comprende muy bien, dado que la mayoría de los Estados europeos permiten el aborto, bien a petición de la embarazada, bien por motivos de salud de la madre ${ }^{45}$.

El único punto en que el TEDH parece sensible a las cuestiones de género en relación con el aborto es con referencia a los derechos del futuro padre. El Tribunal ha afirmado, en el caso Boso contra Italia, Decisión de 5 de septiembre de 2002, que el art. 8 $\mathrm{CEDH}$ no otorga al futuro padre un derecho a exigir ser consultado en relación con la decisión de su pareja de someterse a un aborto. Al menos en esta cuestión, parece que el TEDH reconoce que la esencialmente afectada por el embarazo es la mujer.

El acceso a las técnicas de reproducción asistida. El TEDH ha reconocido un derecho a beneficiarse del progreso científico en materia reproductiva y, por tanto, a utilizar técnicas de reproducción asistida para convertirse en padre/madre a partir del art. $8 \mathrm{CEDH}$ - casos Evans contra Reino Unido, de 10 de abril de 2007 (Gran Sala) y S.H. y otros contra Austria, de 3 de noviembre de 2011 (Gran Sala)_. Ahora bien, el Tribunal de Estrasburgo se ha limitado a analizar la compatibilidad entre dicho precepto y las legislaciones nacionales que limitaban el acceso de los demandantes a las técnicas de reproducción asistida; en ningún caso ha llegado a reconocer una obligación positiva de los

43 Así lo hace, entre otras muchas sentencias, en el caso Evans contra Reino Unido, de 10 de abril de 2007. Vid. M. Díaz Crego, cit., p. 162.

44 Vid, por ejemplo, el Caso Vo contra Francia, de 8 de julio de 2004.

45 M. Díaz Crego, cit., pp. 167-174. 
Estados de costear tales tratamientos ${ }^{46}$. Aunque el TEDH ha impuesto a los Estados algunas exigencias en esta materia, en general, ha concedido un amplio margen de apreciación estatal, basándose en la inexistencia de un consenso europeo sobre el tema.

Analizando la jurisprudencia del TEDH sobre esta materia con perspectiva de género, hay que poner de manifiesto que, a diferencia de lo que se estableció con relación al aborto, cuando se trata del consentimiento de ambos progenitores sobre la posibilidad de destruir embriones, el TEDH ha considerado igual de atendibles la decisión del varón y la de la mujer (caso Evans c. Reino Unido, ya citado).

La gestación subrogada. La denominada «gestación subrogada» es mucho más que una técnica de reproducción asistida. Plantea varios dilemas éticos y sociales pues implica, no sólo a los sujetos que desean ser padres/madres y a los menores, sino también a una tercera persona, la mujer que gesta, cuyos derechos y situación de vulnerabilidad no siempre son tenidos en cuenta en las regulaciones y sentencias sobre la materia. El TEDH ha tenido ocasión de pronunciarse en dos ocasiones sobre la situación de un menor nacido por este medio en un país distinto a aquél en el que los padres comitentes (los que contratan con la mujer gestante) desean inscribir la filiación.

En el caso Mennesson y Labasse contra Francia, de 26 de junio de 2014, el TEDH entendió que la negativa de las autoridades internas francesas a inscribir en el Registro correspondiente la resolución extranjera que fijaba el vínculo entre los padres comitentes y el menor nacido por gestación subrogada en Estados Unidos vulneraba el derecho a la vida privada y familiar del art. $8 \mathrm{CEDH}$.

Sin embargo, en el posterior caso Paradiso y Campanelli contra Italia, de 24 de enero de 2017 (Gran Sala), la decisión fue distinta. En este caso las autoridades italianas retiraron la custodia de un menor nacido por gestación subrogada en Rusia (tras seis meses de convivencia familiar). En Italia está prohibida la gestación subrogada y el Estado italiano tomó esa decisión controvertida como medida para hacer cumplir las leyes internas y «prevenir el desorden». El Tribunal entendió que no se había violado el art. $8 \mathrm{CEDH}$ pues, ante la ausencia de consenso europeo sobre la materia, había que reconocer un amplio margen de apreciación a los Estados. En la argumentación se tuvo en cuenta que no existía vínculo genético entre los padres comitentes y el menor, pero no se tuvo en cuenta el vínculo biológico entre el menor y la madre gestante. Si se hubiese juzgado el caso con perspectiva de género, hubiera sido preciso considerar también la situación y los derechos de esta mujer. Hubo varios Votos Particulares concurrentes y discrepantes. En uno de ellos se afirmaba que la decisión había vulnerado el art. 8 CEDH y en otro que la gestación subrogada es incompatible con la dignidad humana tanto del niño como de la madre gestante.

\section{ALGUNAS CONCLUSIONES}

Después de este análisis de algunas de las principales sentencias del TEDH en materia de igualdad de género y de derechos humanos con perspectiva de género, podemos obtener algunas conclusiones. 
Por lo que se refiere a la jurisprudencia sobre la igualdad, hay que destacar que, a pesar de algún precedente anterior, sólo a partir de 2000 se ha generalizado el reconocimiento de la existencia de discriminaciones por razón de género y, por tanto, de vulneraciones del art. $14 \mathrm{CEDH}$. En su mayor parte, se ha tratado de discriminaciones directas, es decir, aquéllas contenidas expresamente en la norma o medida analizada. En algunos casos, se trataba de normas que perjudicaban a las mujeres, por ejemplo, en el acceso al empleo y a prestaciones y beneficios sociales o en el orden de los apellidos. Pero, en otros casos, se trataba de normas que trataban de proteger a las mujeres y, en estos casos, los recurrentes eran varones. Así ha sucedido en materias como pensiones de viudedad, permisos de paternidad, obligaciones cívicas o condenas penales. El TEDH, en la mayor parte de estas sentencias, ha ido haciéndose eco de la visión actual de la sociedad europea sobre el nuevo papel que juegan hombres y mujeres en el acceso al empleo remunerado y en los cuidados de hijos e hijas. Los nuevos roles son más igualitarios y contradicen los estereotipos clásicos de las sociedades patriarcales.

Sin embargo, falta aún una doctrina clara sobre las normas que protegen la maternidad, algo exigido por los tratados internacionales sobre igualdad de género, como la CEDAW. También se echa en falta un mayor reconocimiento por parte del TEDH de discriminaciones indirectas por razón de género. En cuanto a la jurisprudencia sobre medidas de acción positiva, la doctrina ha puesto de manifiesto que los pronunciamientos del Tribunal no son muy claros y no distinguen adecuadamente entre las auténticas acciones afirmativas, que favorecen la incorporación de las mujeres al trabajo remunerado, y las normas falsamente protectoras de las mujeres, que consolidan su papel tradicional relegado al ámbito doméstico.

En el análisis de las sentencias del TEDH que han versado sobre los derechos de las mujeres, podemos concluir que sólo algunas de ellas han realizado un análisis con perspectiva de género. Ello supone tener en cuenta los estereotipos vigentes en la sociedad patriarcal sobre los roles asignados a mujeres y hombres. Supone también el reconocimiento de la situación histórica de subordinación de las mujeres y la evaluación de si las medidas controvertidas tienden o no a la igualdad real. En la jurisprudencia sobre violencia de género, es destacable el caso Opuz contra Turquía, de 2009, en el que se consideraron vulnerados los arts. 2 y 3 en combinación con el art. $14 \mathrm{CEDH}$. Esta decisión implica el reconocimiento de que la violencia contra las mujeres es el resultado de una situación social de discriminación, es el último baluarte de la desigualdad. Y trae como consecuencia el establecimiento de obligaciones positivas del Estado en la consecución de la igualdad y en la prevención de aquella lacra.

La jurisprudencia del TEDH sobre la trata de mujeres con fines de explotación sexual ha conocido avances, como la consideración de este fenómeno como una vulneración del art. $4 \mathrm{CEDH}$. Pero falta aún un análisis con perspectiva de género, que evalúe la situación de las víctimas y la consideración de esta forma de esclavitud como un trato inhumano y degradante contrario al Convenio. En este sentido parece avanzar el reciente caso V.C. contra Italia, de 2018.

Los derechos sexuales y reproductivos constituyen una materia en la que la perspectiva de género debía ser insoslayable, dado el papel fundamental de las mujeres en la reproducción. La jurisprudencia del TEDH sobre estos derechos presenta contradicciones y puntos oscuros y no siempre se aplica la perspectiva de género, a pesar de algunos pequeños avances. 
TITLE: Main jurisprudential milestones of the ECHR in matters of gender equality

ABSTRACT: The paper analyzes some of the main judgments of the ECHR on gender equality and buman rights with a gender perspective. Since 2000, the Court has issued several judgments recognizing the existence of direct discrimination based on gender. In these judgments, it was echoing the new trend of european society to the equitable distribution of work and family responsibilities between women and men. However, the Court has not argued to the same extent in terms of indirect discrimination or positive action measures. Likewise, in some rulings on women's rights (especially in matters of gender-based violence and sexual and reproductive rights), the ECHR has applied the gender perspective, but has done so in a still insufficient way.

RESUMEN: En el trabajo se realiza un análisis de algunas de las principales sentencias del TEDH en materia de igualdad de género y de derechos humanos con perspectiva de género. Desde 2000, el Tribunal ha dictado varias sentencias que reconocen la existencia de discriminaciones directas por razón de género. En estas sentencias, se ha hecho eco de la nueva tendencia de la sociedad europea a la distribución equitativa de las responsabilidades laborales y familiares entre mujeres y hombres. Sin embargo, el Tribunal no ha argumentado en la misma medida en términos de discriminaciones indirectas o de medidas de acción positiva. Asimismo, en algunas sentencias sobre derechos de las mujeres (en especial, en materia de violencia de género y de derechos sexuales y reproductivos), el TEDH ha aplicado la perspectiva de género, pero lo ba hecho de forma todavía muy insuficiente.

KEY WORDS: Gender equality, gender mainstreaming, European Court of Human Rights, gender violence, sexual and reproductive rights.

Palabras CLAVE: Igualdad de género, perspectiva de género, Tribunal Europeo de Derechos Humanos, violencia de género, derechos sexuales y reproductivos.

FECHA DE RECEPCIÓN: 24.06.2018 FECHA DE ACEPTACIÓN: 13.09.2018 